Título artículo / Títol article:

Autores / Autors:
Centrally formed acetaldehyde mediates ethanol-induced brain PKA activation

Revista:

Neuroscience letters

Versión / Versió:

Pre-print

Cita bibliográfica / Cita bibliogràfica (ISO 690):

TARRAGON, E.; BALIÑO, P.; GONZÁLEZ ARAGÓN, C. M. Centrally formed acetaldehyde mediates ethanol-induced brain PKA activation. Neuroscience letters, 2014, vol. 580, p. 68-73.

url Repositori UJI:

http://hdl.handle.net/10234/127657 


\section{Accepted Manuscript}

Title: Centrally Formed Acetaldehyde Mediates Ethanol-Induced Brain Pka Activation

Author: E. Tarragon P. Baliño C.M.G. Aragon

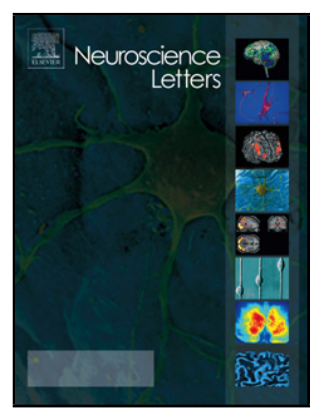

PII: S0304-3940(14)00627-2

DOI: http://dx.doi.org/doi:10.1016/j.neulet.2014.07.046

Reference: NSL 30738

To appear in:

Neuroscience Letters

Received date:

23-5-2014

Revised date: 24-7-2014

Accepted date:

25-7-2014

Please cite this article as: E. Tarragon, P. Baliño, C.M.G. Aragon, Centrally Formed Acetaldehyde Mediates Ethanol-Induced Brain Pka Activation, Neuroscience Letters (2014), http://dx.doi.org/10.1016/j.neulet.2014.07.046

This is a PDF file of an unedited manuscript that has been accepted for publication. As a service to our customers we are providing this early version of the manuscript. The manuscript will undergo copyediting, typesetting, and review of the resulting proof before it is published in its final form. Please note that during the production process errors may be discovered which could affect the content, and all legal disclaimers that apply to the journal pertain. 


\section{Highlights}

- EtOH administration in vivo enhances PKA activity in the brain

- cAMP-PKA pathway is involved in the behavioral response to EtOH

- Centrally formed acetaldehyde is responsible for several effects induced by $\mathrm{EtOH}$

- EtOH-induced PKA activation is reduced when central acetaldehyde activity decreases

- cAMP-PKA signaling cascade promoted by EtOH in vivo is dependent on acetaldehyde 


\title{
CENTRALLY FORMED ACETALDEHYDE MEDIATES ETHANOL-INDUCED BRAIN PKA
}

\section{ACTIVATION}

\author{
Tarragon $\mathrm{E}^{1,2}$, Baliño $\mathrm{P}^{1,2}$, Aragon $\mathrm{CMG}{ }^{1^{*}}$ \\ ${ }^{1}$ Área de Psicobiología, Universitat Jaume I, Castellon de la Plana (SPAIN); ${ }^{2}$ Authors \\ contributed equally to this work
}

* Corresponding author:

Prof. Carlos M. G. Aragón, PhD

Dept. Psychobiology

Universitat Jaume I

Avinguda Vicent Sos Baynat, s/n

E-12071 Castelló de la Plana (Spain)

Tel.: +34 964729835

aragon@psb.uji.es

\section{Abstract}

Centrally formed acetaldehyde has proven to be responsible for several psychopharmacological effects induced by ethanol. In addition, it has been suggested that the cAMP-PKA signaling transduction pathway plays an important role in the modulation of several ethanol-induced behaviors. Therefore, we hypothesized that acetaldehyde might be ultimately responsible for the activation of this intracellular pathway. We used three pharmacological agents that modify acetaldehyde activity ( $\alpha$-Lipoic acid, aminotriazole, and D-penicillamine) to study the role of this metabolite on EtOH-induced PKA activation in mice. Our results show that the injection of $\alpha$-Lipoic acid, aminotriazole and D-penicillamine prior to acute $\mathrm{EtOH}$ administration effectively blocks the PKA-enhanced response to $\mathrm{EtOH}$ in the brain. These results strongly support the hypothesis of a selective release of acetaldehyde-dependent $\mathrm{Ca} 2+$ as the mechanism involved in the neurobehavioral effects elicited by $\mathrm{EtOH}$.

Keywords: acetaldehyde, PKA, ethanol 


\section{Introduction}

Ethanol $(\mathrm{EtOH})$ is one of the most widely consumed substances of abuse, and yet the molecular mechanism by which it exerts its effects on behavior is still not understood [1]. It is known that $\mathrm{EtOH}$ is centrally metabolized into acetaldehyde by a combination of the enzyme catalase and hydrogen peroxide (H2O2) [2-4]. This central metabolite has been shown to be responsible for some of the behavioral and neurophysiological effects elicited by EtOH $[5,6]$. In this sense, there is evidence showing that the manipulation of central acetaldehyde through the $\alpha$-Lipoic acid (LA) scavenging of $\mathrm{H} 2 \mathrm{O} 2$ [7-10], the catalase inhibition by 3-amino-1,2,4-triazole (aminotriazole, AT) [3,11-13], and acetaldehyde inactivation by D-penicillamine (D-Pen) [14-18] are capable of preventing different behavioral outcomes resulting from acute EtOH exposure.

The cAMP-PKA cellular signaling pathway has been described as an important mechanism involved in the neurobiological response to $\mathrm{EtOH}[19,20]$. There is evidence in vitro and in vivo showing an activation of the cAMP signaling cascade following EtOH exposure [2124]. In addition, it has been demonstrated that manipulations of the cAMP-PKA pathway modulate some of the $\mathrm{EtOH}$-induced responses at the behavioral level $[25,26]$. Therefore, the PKA activity elicited by $\mathrm{EtOH}$ has been suggested as critical in some behavioral effects induced by this alcohol. However, the particular mechanism by which this EtOH/cAMP-PKA interaction occurs has not yet been clarified in detail.

Considering that acetaldehyde has proven to be responsible for many different EtOHinduced behaviors, and that this alcohol activates the cAMP-PKA signaling pathway, we hypothesized that acetaldehyde might be ultimately responsible for the activation of this intracellular pathway. Hence, we aimed to study the role of central acetaldehyde on EtOHinduced PKA activation. To do this, we used different pharmacological agents that have previously proven effective in preventing central acetaldehyde formation following EtOH administration, such as LA [7,9,27], AT [12-14], and D-Pen [16,18]. We have assessed whether these pharmacological manipulations alter the PKA activity induced by EtOH administration. 
PKA activity was evaluated taking into consideration the results of such activation using a subset of phosphorylable substrate consensus motifs as a kinase footprint [23,24].

\section{Material and methods}

\section{$\underline{\text { Animals }}$}

For this work, we used a total of 4-6 male CD-I mice (Harlan, Interfauna) per group. All animals, aged 4-6 weeks upon arrival, were housed 3 per cage in an acclimated quarantine room, in which they remained for a week. After this quarantine period, mice were moved into a colony room at least one week before the experiments started. The colony room was maintained at a temperature of $21 \pm 1^{\circ} \mathrm{C}$ and controlled under a 12-h light/dark cycle (lights on at 8 a.m.). Food and water were provided ad libitum throughout the study. All experimental procedures complied with the European Community Council Directive (2010/63/EU).

\section{$\underline{\text { Drugs }}$}

$\mathrm{EtOH}$, purchased from Panreac (Barcelona, Spain), was diluted to $20 \%(\mathrm{v} / \mathrm{v})$ in $0.9 \%$ (w/v) physiological saline, which was also used as the vehicle. LA (Sigma-Aldrich Química, Madrid, Spain) was dissolved in Dulbecco's phosphate-buffered saline, using a minimum possible amount of $1 \mathrm{M} \mathrm{NaOH}$ solution. The final $\mathrm{pH}$ of the resulting solution was $7 \pm 1$. AT and D-Pen (Sigma-Aldrich Química, Madrid, Spain) were both diluted in $0.9 \%(\mathrm{w} / \mathrm{v})$ physiological saline.

\section{Experimental procedure}

All animals ( $n=4-6$ per group) were moved from their home cages to the procedure room 30 minutes before the start of the experiment to allow them to acclimatize to the environmental conditions. Three different experimental phases were conducted. In the first experiment, animals were pretreated with LA ( 0 or $100 \mathrm{mg} / \mathrm{Kg}$, i.p.), and 30 minutes later $\mathrm{EtOH}$ (0 or $2.5 \mathrm{~g} / \mathrm{Kg}$, i.p.) was injected [7]. In the second experiment, AT (0 or $1 \mathrm{~g} / \mathrm{Kg}$, i.p.) was

administered $4 \mathrm{~h}$ prior to the $\mathrm{EtOH}$ challenge (0 or $2.5 \mathrm{~g} / \mathrm{Kg}$, i.p.) [12]. Lastly, in the third 
experiment D-Pen (0 or $75 \mathrm{mg} / \mathrm{Kg}$, i.p.) was administered 30 minutes before $\mathrm{EtOH}$ (0 or 2.5 g/Kg, i.p.) injection [14]. For all three experimental phases, animals were sacrificed 15 minutes after EtOH administration. Brains were immediately removed and dissected. PKA activity was measured using a subset of phosphorylable substrate consensus motifs as a kinase footprint $[23,24]$.

\section{$\underline{\text { Western blot }}$}

For determination of PKA, $20 \mu \mathrm{g}$ of protein extract from three brain structures (frontal cortex, striatum and hypothalamus; $n=4-6$ per group) were run in duplicate into pure nitrocellulose membranes $(0.45 \mathrm{~mm})$ using standard techniques. Membranes were incubated overnight with a primary antiphosphorylated PKA substrate motif $(1: 6,000$; Cell Signaling Technology, Beverly, MA) and then with HRP-conjugated secondary antibody anti-rabbit (1:20,000). Anti-GAPDH antibody (1:40,000; Sigma-Aldrich Química) was used as a loading control. Proteins were visualized using an enhanced chemi-luminescence system (Amersham Pharmacia Biotech, Madrid, Spain). The relative intensities were quantified and analyzed individually with Sigma-Gel image analysis software version 1.0 (Jandel Scientific, Madrid, Spain). Density values were averaged to obtain a normalized value. The average of these normalized values in the saline-treated group was arbitrarily considered to be $100 \%$ and then used for calculations involving all the different experimental manipulations.

\section{$\underline{\text { Statistical analysis }}$}

For the analysis, the relative increase was considered to be the dependent variable. A one- or two-way ANOVA was performed when required. Newman-Keuls post hoc comparisons were used in experiments 1 and 3. The Tukey HSD post hoc test was applied in the analyses of the results obtained in experiment 2 because it is highly conservative against type I error and it does not require a significant interaction between factors [28]. All statistical analyses were performed using the Statistica 9.0 (StarSoft, Tulsa, OK, USA) software package. 


\section{Results}

\section{$\underline{P K A}$ activation after the administration of $\alpha$-lipoic acid}

In this experiment, we assessed the role of the catalase- $\mathrm{H} 2 \mathrm{O} 2$ system in the $\mathrm{EtOH}$ induced activation of the PKA. Pretreatment with the $\mathrm{H} 2 \mathrm{O} 2$ scavenger LA resulted in a decreased intensity of the immunoreactive bands in all the structures in the study. Figure 1 reflects the effects of LA pretreatment on the EtOH-induced activation of PKA on the cortex (A), striatum (B), and hypothalamus (C). Two-way ANOVA (pretreatment $x$ treatment) showed a lack of effect both for pretreatment and treatment factor in cortex and striatum. A significant main effect was found for the treatment $[F(1,18)=11.25, p<0.01]$ and pretreatment $[F(1,18)=19.03, p<0.01]$ factor in the hypothalamus. Both factors (pretreatment $x$ treatment) interact in all the structures of the study: the cortex $[F(1,17)=7.76, p<0.05]$, striatum $[F(1,18)=10.27, p<0.01]$ and hypothalamus $[F(1,18)=13.69, p<0.01]$. Post hoc comparisons indicate an activating effect of the PKA after EtOH injection when compared to its saline control for cortex $(p<0.05)$, striatum $(p<0.05)$, and hypothalamus $(p<0.01)$. Furthermore, no statistical differences were found in the PKA fingerprint among groups pretreated with LA for all the structures in the study.

\section{$\underline{\text { PKA activation after the administration of aminotriazole }}$}

Here, we have studied the role of the catalase- $\mathrm{H} 2 \mathrm{O} 2$ system in $\mathrm{EtOH}$-induced activation of PKA. Pretreatment with the catalase inhibition agent AT resulted in a reduction in the PKA activity elicited by EtOH. Figure 2 shows the effect of AT administration on the PKA fingerprint in (A) cortex, (B) striatum, and (C) hypothalamus. Two-way ANOVA (pretreatment $x$ treatment) showed a significant main effect for EtOH treatment in the cortex $[F(1,18)=5.71, p<0.05]$ and hypothalamus $[F(1,18)=10.40, p<0.05]$. The pretreatment factor was found to be significant in the hypothalamus $[F(1,18)=6.66, p<0.05]$. An interaction effect (pretreatment $x$ treatment) was also found in the striatum $[F(1,17)=8.62, p<0.05]$. 
However, no significant interaction was found for the cortex $[F(1,18)=2.51]$ or the hypothalamus $[F(1,18)=2.55]$. Thus, we selected Tukey's HSD post hoc comparisons to analyze the three structures in this experiment. Tukey's HSD post hoc analyses demonstrated that pretreatment with $\mathrm{EtOH}$ increased PKA activity for all the structures in the study. Moreover, no statistical differences were found among groups pretreated with AT.

\section{$\underline{P K A \text { activation after the administration of D-penicillamine }}$}

Here, we aimed to study the role of centrally formed acetaldehyde on ethanol-elicited PKA activation. Pretreatment with the acetaldehyde inactivating agent D-pen produced a reduction in the EtOH-induced activation of PKA. Figure 3 reflects the effect of D-pen administration on EtOH-activated PKA in (A) cortex, (B) striatum, and (C) hypothalamus. Twoway ANOVA (pretreatment $x$ treatment) showed a significant main effect for EtOH treatment in all the structures in the study, i.e., the cortex $[F(1,15)=25.77, p<0.01$, striatum $[F(1,18)=12.58, p<0.01]$, and hypothalamus $[F(1,22)=5.19, p<0.05]$. Moreover, $\mathrm{D}$ pen pretreatment was found to be significant in the cortex $[F(1,15)=26.35, p<0.01]$, striatum $[F(1,18)=15.43, p<0.01]$, and hypothalamus $[F(1,22)=15.78, p<0.01]$. Both factors (pretreatment $x$ treatment) interact in the cortex $[F(1,15)=10.22, p<0.01]$, striatum $[F(1,18)=13.52, p<0.01]$, and hypothalamus $[F(1,22)=12.83, p<0.01]$. Post hoc comparisons indicate an activating effect of $\mathrm{PKA}$ after $\mathrm{EtOH}$ injection when compared to its saline control for all the structures in the study, $p<0.01$. Furthermore, no significant differences were found among groups pretreated with D-pen.

\section{Discussion}

In this work, we aimed to explore the role of centrally formed acetaldehyde on EtOHinduced activation of PKA. In agreement with previously published data [23,24], our results show that $\mathrm{EtOH}$ administration to mice elicited PKA activation in different brain areas (prefrontal 
cortex, striatum, and hypothalamus). Catalase- $\mathrm{H} 2 \mathrm{O} 2$ system blockade by pretreatment with LA and $\mathrm{AT}$ resulted in a reduction in $\mathrm{EtOH}$-induced activation of PKA. Furthermore, pretreatment with the acetaldehyde inactivator D-Pen also produced a decrease in PKA activity observed after $\mathrm{EtOH}$ administration. These data suggest a role of centrally formed acetaldehyde in $\mathrm{EtOH}$ elicited PKA activation.

The effects of EtOH on PKA activity have been shown in neuronal cell cultures $[29,30]$. Again, in vivo experiments have demonstrated an up-regulation of the cAMP-PKA cascade after $\mathrm{EtOH}$ administration [22,23,31]. In the present work, we aimed to explore the functional consequences of brain acetaldehyde modulation on EtOH-stimulated PKA activity. Thus, we have used a subset of phosphorylable consensus motifs as a PKA-activated fingerprint [22,23]. Previous literature has demonstrated that $\mathrm{EtOH}$ administration promotes an increased steady response at different band intensities $(90,100$ and $140 \mathrm{kDa})$ in mice brains [22,23]. Consistent with these results, we have found a similar band-enhanced response after $\mathrm{EtOH}$ administration in the areas in the study. Conversely, when acetaldehyde manipulations were administered prior to $\mathrm{EtOH}$, the densitometric analysis indicated a reduction in the band intensity when compared to control animals. These data suggest that centrally formed acetaldehyde is critical to further activate the cAMP-PKA cascade promoted by EtOH exposure.

Acetaldehyde has been suggested as a neuroactive agent responsible for different EtOH neurobehavioral effects [32]. Thus, in order to ascertain the role of acetaldehyde in EtOHinduced activation of PKA, we have used three pharmacological approaches. Firstly, we have used LA as an $\mathrm{H} 2 \mathrm{O} 2$ scavenging agent. This compound acts as an $\mathrm{H} 2 \mathrm{O} 2$ scavenger and it has been demonstrated that, if administered systemically, it modulates brain $\mathrm{H} 2 \mathrm{O} 2$ levels, and consequently catalase activity [7,27]. Secondly, we used the noncompetitive catalase inhibitor AT. This compound can also be administered systemically, and prevents acetaldehyde formation after EtOH administration [3,33]. Finally, we have used the acetaldehydesequestering agent D-Pen, which prevents interaction between the centrally formed 
acetaldehyde and the neural substrate $[14,15,17]$. Despite the fact that these agents differed in their molecular mechanism of action to block acetaldehyde production, our results showed that EtOH metabolism at a central level appears to be critical to elicit further PKA activation.

A great body of evidence has demonstrated that the activation of the cAMP signaling cascade appears to be a major cellular response to EtOH in vivo and in different cell preparations $[21,23,30]$. However, the particular mechanism by which this activation occurs has still not been clarified in detail. In this respect, recently published data from our laboratory have demonstrated that intracellular calcium ( $\mathrm{Ca} 2+)$ appears to be a key factor in this $\mathrm{EtOH}$-induced PKA activation [34-36]. Thus, different manipulations addressed to modulate intracellular $\mathrm{Ca2+}$ levels resulted in a selective blockade of the PKA response elicited by $\mathrm{EtOH}$ [34]. Interestingly, it has been found that acetaldehyde administration at biologically relevant concentrations ranging from 1-10 $\mu \mathrm{M}$ promotes Ca2+ release in different cell preparations [37-40]. Moreover, these authors also found that manipulations affecting EtOH oxidation to acetaldehyde were able to modulate such acetaldehyde-mediated $\mathrm{Ca} 2+$ release.

At the behavioral level, the PKA signaling transduction pathway has proven to be involved in the modulation of several EtOH-induced behaviors. Manipulations of the cAMP-PKAdependent cascade modulate $\mathrm{EtOH}$ intake [24], EtOH-induced sensitization [26,41], and EtOH sensitivity [42]. In this regard, previous work by our group has demonstrated that the alteration of cytoplasmic $\mathrm{Ca} 2+$ levels reduced $\mathrm{EtOH}$ intake, EtOH-induced locomotor activity, and affected EtOH sensitivity $[34,35]$. Given this, it has been suggested that intracellular Ca2+ levels may be a key factor that determines the cAMP-signaling response, and consequently the behavioral outcome observed after EtOH administration.

Parallel to these interesting findings, a great body of evidence has proven that central acetaldehyde plays a key role in different EtOH-promoted behaviors. Thus, manipulations focused on decreasing or blocking acetaldehyde production, such as catalase inhibition by the use of AT or acetaldehyde sequestration with the agent D-Pen, resulted in a reduction in EtOH- 
induced locomotor activity [14,17], EtOH intake [15], EtOH-induced place preference [15,27], social recognition [43], loss of righting reflex [44], and anxiety [45]. Furthermore, a reduction of the brain levels of compound I by the pharmacological manipulation of the cellular oxidative state also played a critical role in the behavioral response promoted by EtOH. $\mathrm{H} 2 \mathrm{O} 2$ scavenging with LA or Ebselen have proven to modulate $\mathrm{EtOH}$-induced locomotor activity [7,36], EtOH intake [8], and EtOH-induced conditioned place preference [27].

In sum, we demonstrate that, when administered previously, acetaldehyde inactivation agents effectively inhibit PKA activation following EtOH exposure. Therefore, this work provides valuable insight into the putative intracellular mechanism through which $\mathrm{EtOH}$ might be exerting its effects. Moreover, these data support the idea that, through the PKA-involved intracellular $\mathrm{Ca} 2+$ pathway, centrally formed acetaldehyde is mainly responsible for the appearance of the psychopharmacological effects of EtOH.

\section{Conclusion}

We have demonstrated that the activation of the CAMP-PKA signaling cascade promoted by $\mathrm{EtOH}$ administration in vivo is dependent on the central catalasemic metabolism of $\mathrm{EtOH}$. Thus, manipulations, which reduced the rate of centrally formed acetaldehyde, resulted in a decreased EtOH-induced activation of PKA. Moreover, all these results together with the previous literature strongly support the hypothesis of a selective release of acetaldehyde-dependent $\mathrm{Ca} 2+$ from the ER as the mechanism involved in the neurobehavioral effects elicited by $\mathrm{EtOH}$.

\section{Acknowledgements}

This research was supported by a grant from the Spanish Ministerio de Ciencia e Innovacion (PSI2011-28934/ PSIC). Pablo Baliño was supported by a fellowship from the CICYT (BES2009-024438). Ernesto Tarragon was supported at the time by Red de Trastornos Adictivos, Ministerio de Sanidad y Politica Social (RD06/0001/0028), Spain. 


\section{References}

1. R.A. Harris, J.R. Trudell, S.J. Mihic, Ethanol's molecular targets, Science signaling 1 (2008) re7.

2. J.F. Cohen, J.A. Elberling, E.G. DeMaster, R.C. Lin, H.T. Nagasawa, N-Terminal dipeptides of $\mathrm{D}(-)$-penicillamine as sequestration agents for acetaldehyde, Journal of medicinal chemistry 43 (2000) 1029-1033.

3. C.M.G. Aragon, F. Rogan, Z. Amit, Ethanol metabolism in rat brain homogenates by a catalase-H2O2 system, Biochemical pharmacology 44 (1992) 93-98.

4. S.M. Zimatkin, A.L. Buben, Ethanol oxidation in the living brain, Alcohol and alcoholism $42(2007)$ 529-532.

5. X.S. Deng, R.A. Deitrich, Putative role of brain acetaldehyde in ethanol addiction, Current drug abuse reviews 1 (2008) 3-8.

6. L. Hipolito, M.J. Sanchez, A. Polache, L. Granero, Brain metabolism of ethanol and alcoholism: an update, Current drug metabolism 8 (2007) 716-727.

7. J.C. Ledesma, C.M.G. Aragon, alpha-Lipoic acid, a scavenging agent for $\mathrm{H}(2) \mathrm{O}(2)$, reduces ethanol-stimulated locomotion in mice, Psychopharmacology 219 (2012) 171180.

8. J.C. Ledesma, P. Balino, C.M.G. Aragon, Reduction in central $\mathrm{H}(2) \mathrm{O}(2)$ levels prevents voluntary ethanol intake in mice: a role for the brain catalase- $\mathrm{H}(2) \mathrm{O}(2)$ system in alcohol binge drinking, Alcoholism, clinical and experimental research 38 (2014) 60-67.

9. A.T. Peana, G. Muggironi, G. Fois, M. Diana, Alpha-lipoic acid reduces ethanol selfadministration in rats, Alcoholism, clinical and experimental research 37 (2013) 18161822.

10. M. Melis, E. Carboni, P. Caboni, E. Acquas, Key role of salsolinol in ethanol actions on dopamine neuronal activity of the posterior ventral tegmental area, Addiction biology (2013). 
11. C.M.G. Aragon, Z. Amit, The effect of 3-amino-1,2,4-triazole on voluntary ethanol consumption: evidence for brain catalase involvement in the mechanism of action, Neuropharmacology 31 (1992) 709-712.

12. D. Escarabajal, M. Miquel, C.M.G. Aragon, A psychopharmacological study of the relationship between brain catalase activity and ethanol-induced locomotor activity in mice, Journal of studies on alcohol 61 (2000) 493-498.

13. L. Font, M. Miquel, C.M.G. Aragon, Involvement of brain catalase activity in the acquisition of ethanol-induced conditioned place preference, Physiology \& behavior 93 (2008) 733-741.

14. L. Font, M. Miquel, C.M.G. Aragon, Prevention of ethanol-induced behavioral stimulation by D-penicillamine: a sequestration agent for acetaldehyde, Alcoholism, clinical and experimental research 29 (2005) 1156-1164.

15. A. Orrico, L. Hipolito, M.J. Sanchez-Catalan, L. Marti-Prats, T. Zornoza, L. Granero, A. Polache, Efficacy of D-penicillamine, a sequestering acetaldehyde agent, in the prevention of alcohol relapse-like drinking in rats, Psychopharmacology 228 (2013) 563575.

16. A.T. Peana, P. Enrico, A.R. Assaretti, E. Pulighe, G. Muggironi, M. Nieddu, A. Piga, A. Lintas, M. Diana, Key role of ethanol-derived acetaldehyde in the motivational properties induced by intragastric ethanol: a conditioned place preference study in the rat, Alcoholism, clinical and experimental research 32 (2008) 249-258.

17. L. Marti-Prats, M.J. Sanchez-Catalan, L. Hipolito, A. Orrico, T. Zornoza, A. Polache, L. Granero, Systemic administration of D-penicillamine prevents the locomotor activation after intra-VTA ethanol administration in rats, Neuroscience letters 483 (2010) 143-147.

18. S.M. March, P. Abate, N.E. Spear, J.C. Molina, The role of acetaldehyde in ethanol reinforcement assessed by Pavlovian conditioning in newborn rats, Psychopharmacology 226 (2013) 491-499. 
19. E. Quertemont, S. Tambour, P. Bernaerts, S.M. Zimatkin, E. Tirelli, Behavioral characterization of acetaldehyde in C57BL/6J mice: locomotor, hypnotic, anxiolytic and amnesic effects, Psychopharmacology 177 (2004) 84-92.

20. L.H. Jiang, J. Wang, X.L. Wei, Q.Y. Liang, T.T. Cheng, Exogenous sodium hydrosulfide can attenuate naloxone-precipitated withdrawal syndromes and affect cAMP signaling pathway in heroin-dependent rat's nucleus accumbens, European review for medical and pharmacological sciences 16 (2012) 1974-1982.

21. I. Diamond, A.S. Gordon, Cellular and molecular neuroscience of alcoholism, Physiological reviews 77 (1997) 1-20.

22. J.W. Maas, Jr., S.K. Vogt, G.C. Chan, V.V. Pineda, D.R. Storm, L.J. Muglia, Calciumstimulated adenylyl cyclases are critical modulators of neuronal ethanol sensitivity, The Journal of neuroscience : the official journal of the Society for Neuroscience 25 (2005) 4118-4126.

23. P. Balino, J.C. Ledesma, C.M.G. Aragon, In vivo study of ethanol-activated brain protein kinase A: manipulations of $\mathrm{Ca} 2+$ distribution and flux, Alcoholism, clinical and experimental research 38 (2014) 629-640.

24. G. Wand, M. Levine, L. Zweifel, W. Schwindinger, T. Abel, The cAMP-protein kinase A signal transduction pathway modulates ethanol consumption and sedative effects of ethanol, The Journal of neuroscience : the official journal of the Society for Neuroscience 21 (2001) 5297-5303.

25. S.C. Pandey, H. Zhang, A. Roy, T. Xu, Deficits in amygdaloid cAMP-responsive element-binding protein signaling play a role in genetic predisposition to anxiety and alcoholism, The Journal of clinical investigation 115 (2005) 2762-2773.

26. D.M. Hayes, J.R. Fee, T.J. McCown, D.J. Knapp, G.R. Breese, I. Cubero, F. Carvajal, J.M. Lerma-Cabrera, M. Navarro, T.E. Thiele, Neuropeptide $Y$ signaling modulates the 
expression of ethanol-induced behavioral sensitization in mice, Addiction biology 17 (2012) 338-350.

27. J.C. Ledesma, C.M.G. Aragon, Acquisition and reconditioning of ethanol-induced conditioned place preference in mice is blocked by the $\mathrm{H}(2) \mathrm{O}(2)$ scavenger alpha lipoic acid, Psychopharmacology 226 (2013) 673-685.

28. G.M. Wilcox, J.R. Beck, Early invasive cancer in adenomatous colonic polyps ("malignant polyps"). Evaluation of the therapeutic options by decision analysis, Gastroenterology 92 (1987) 1159-1168.

29. D.P. Dohrman, I. Diamond, A.S. Gordon, Ethanol causes translocation of cAMPdependent protein kinase catalytic subunit to the nucleus, Proceedings of the National Academy of Sciences of the United States of America 93 (1996) 10217-10221.

30. O. Asher, T.D. Cunningham, L. Yao, A.S. Gordon, I. Diamond, Ethanol stimulates cAMPresponsive element (CRE)-mediated transcription via CRE-binding protein and CAMPdependent protein kinase, The Journal of pharmacology and experimental therapeutics 301 (2002) 66-70.

31. J. Li, Y.H. Li, X.R. Yuan, Changes of phosphorylation of cAMP response element binding protein in rat nucleus accumbens after chronic ethanol intake: naloxone reversal, Acta pharmacologica Sinica 24 (2003) 930-936.

32. M. Correa, J.D. Salamone, K.N. Segovia, M. Pardo, R. Longoni, L. Spina, A.T. Peana, S. Vinci, E. Acquas, Piecing together the puzzle of acetaldehyde as a neuroactive agent, Neuroscience and Biobehavioral Reviews 36 (2012) 404-430.

33. J.C. Ledesma, L. Font, C.M.G. Aragon, The H2O2 scavenger ebselen decreases ethanol-induced locomotor stimulation in mice, Drug and alcohol dependence 124 (2012) 42-49. 
34. E. Tarragon, P. Balino, C.M.G. Aragon, Dantrolene blockade of ryanodine receptor impairs ethanol-induced behavioral stimulation, ethanol intake and loss of righting reflex, Behavioural brain research 233 (2012) 554-562.

35. P. Balino, L. Monferrer, R. Pastor, C.M.G. Aragon, Intracellular calcium chelation with BAPTA-AM modulates ethanol-induced behavioral effects in mice, Experimental neurology 234 (2012) 446-453.

36. P. Balino, J.C. Ledesma, C.M.G. Aragon, Role of Ca2+/Calmodulin on ethanol neurobehavioral effects, Psychopharmacology (in press) (2014).

37. T. Oba, T. Ishikawa, T. Murayama, Y. Ogawa, M. Yamaguchi, $\mathrm{H}(2) \mathrm{O}(2)$ and ethanol act synergistically to gate ryanodine receptor/calcium-release channel, American journal of physiology. Cell physiology 279 (2000) C1366-1374.

38. T. Oba, Y. Maeno, Acetaldehyde alters Ca2t-release channel gating and muscle contraction in a dose-dependent manner, American journal of physiology. Cell physiology 286 (2004) C1188-1194.

39. A. Gonzalez, J.A. Pariente, G.M. Salido, Ethanol stimulates ROS generation by mitochondria through $\mathrm{Ca} 2+$ mobilization and increases GFAP content in rat hippocampal astrocytes, Brain research 1178 (2007) 28-37.

40. T. Oba, Y. Maeno, M. Nagao, N. Sakuma, T. Murayama, Cellular redox state protects acetaldehyde-induced alteration in cardiomyocyte function by modifying $\mathrm{Ca} 2+$ release from sarcoplasmic reticulum, American journal of physiology. Heart and circulatory physiology 294 (2008) H121-133.

41. B.K. Tolliver, L.B. Ho, L.M. Fox, S.P. Berger, Necessary role for ventral tegmental area adenylate cyclase and protein kinase $\mathrm{A}$ in induction of behavioral sensitization to intraventral tegmental area amphetamine, The Journal of pharmacology and experimental therapeutics 289 (1999) 38-47. 
42. T.E. Thiele, B. Willis, J. Stadler, J.G. Reynolds, I.L. Bernstein, G.S. McKnight, High ethanol consumption and low sensitivity to ethanol-induced sedation in protein kinase Amutant mice, The Journal of neuroscience : the official journal of the Society for Neuroscience 20 (2000) RC75.

43. H.M. Manrique, M. Miquel, C.M.G. Aragon, Brain catalase mediates potentiation of social recognition memory produced by ethanol in mice, Drug and alcohol dependence 79 (2005) 343-350.

44. M. Correa, C. Sanchis-Segura, C.M.G. Aragon, Influence of brain catalase on ethanolinduced loss of righting reflex in mice, Drug and alcohol dependence 65 (2001) 9-15.

45. M. Correa, H.M. Manrique, L. Font, M.A. Escrig, C.M.G. Aragon, Reduction in the anxiolytic effects of ethanol by centrally formed acetaldehyde: the role of catalase inhibitors and acetaldehyde-sequestering agents, Psychopharmacology 200 (2008) 455464. 
Figure 1. PKA activation after LA administration. Immunoblot analysis and quantification of the PKA substrate. Left panels show the densitometric analysis performed to quantify the relative intensity of the bands (arbitrary units) after pretreatment with LA (0 or $100 \mathrm{mg} / \mathrm{kg}$, i.p.) 30 minutes before $\mathrm{EtOH}$ ( 0 or $2.5 \mathrm{~g} / \mathrm{kg}$, i.p.) challenge. Right panels show a representative Western blot of the PKA fingerprint after Vehicle or EtOH administration. Anti-GAPDH blots shown equal protein loading. (A) Cortex, (B) striatum, (C) hypothalamus. Depicted is the mean \pm SEM. * $p<0.05,{ }^{* *} p<0.01$ significantly different from its respective Vehicle control. S, saline; E, EtOH; LA, a-lipioc acid.

Figure 2. PKA activation after AT administration. Immunoblot analysis and quantification of the PKA substrate. Left panels show the densitometric analysis performed to quantify the relative intensity of the bands (arbitrary units) after pretreatment with AT (0 or $1 \mathrm{~g} / \mathrm{kg}$, i.p.) 4 hours before $\mathrm{EtOH}$ (0 or $2.5 \mathrm{~g} / \mathrm{kg}$, i.p.) challenge. Right panels show a representative Western blot of the PKA fingerprint after Vehicle or EtOH administration. Anti-GAPDH blots shown equal protein loading. (A) Cortex, (B) striatum, (C) hypothalamus. Depicted is the mean \pm SEM. * $p<$ $0.05,{ }^{* \star} p<0.01$ significantly different from its respective Vehicle control;. S, saline; E, EtOH; AT, aminotriazole.

Figure 3. PKA activation after D-Pen administration. Immunoblot analysis and quantification of the PKA substrate. Left panels show the densitometric analysis performed to quantify the relative intensity of the bands (arbitrary units) after pretreatment with D-Pen ( 0 or $75 \mathrm{mg} / \mathrm{kg}$, i.p.) 30 minutes before $\mathrm{EtOH}$ ( 0 or $2.5 \mathrm{~g} / \mathrm{kg}$, i.p.) challenge. Right panels show a representative Western blot of the PKA fingerprint after Vehicle or EtOH administration. Anti-GAPDH blots shown equal protein loading. (A) Cortex, (B) striatum, (C) hypothalamus. Depicted is the mean \pm SEM. ${ }^{* *} \mathrm{p}<0.01$ significantly different from its respective Vehicle control. S, saline; E, EtOH; D-Pen, D-penicillamine. 
Figure
\begin{tabular}{ll} 
Figure 1 \\
$\qquad \begin{array}{ll}{ }^{200} \\
{ }^{2}\end{array} \quad$ * \\
\hline $\mathrm{E}$
\end{tabular}

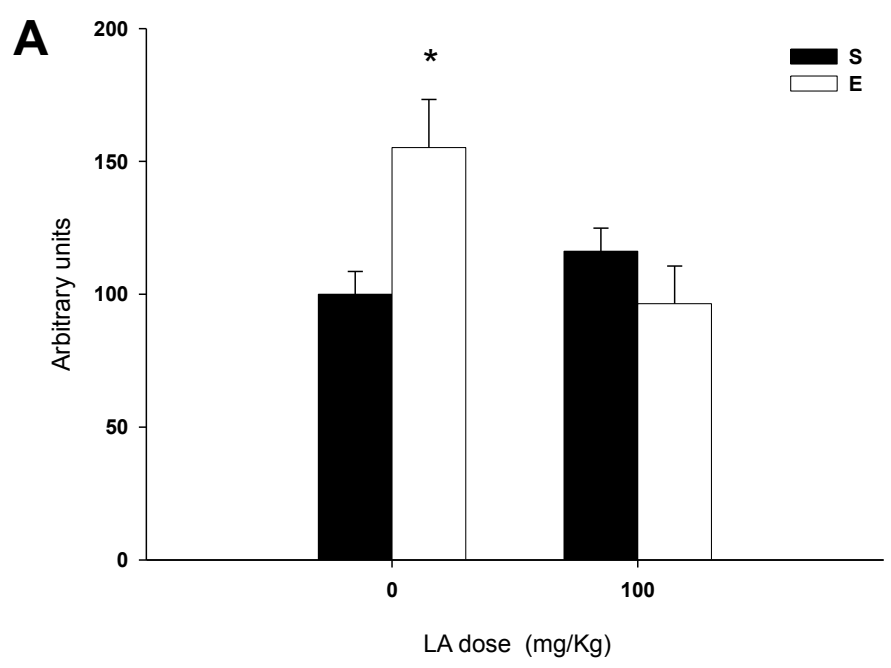

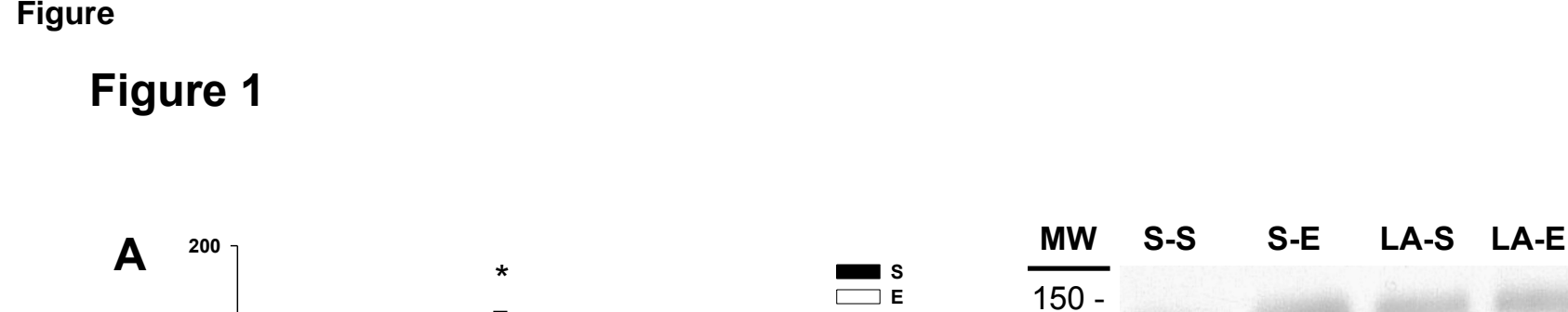

\section{GAPDH}

B
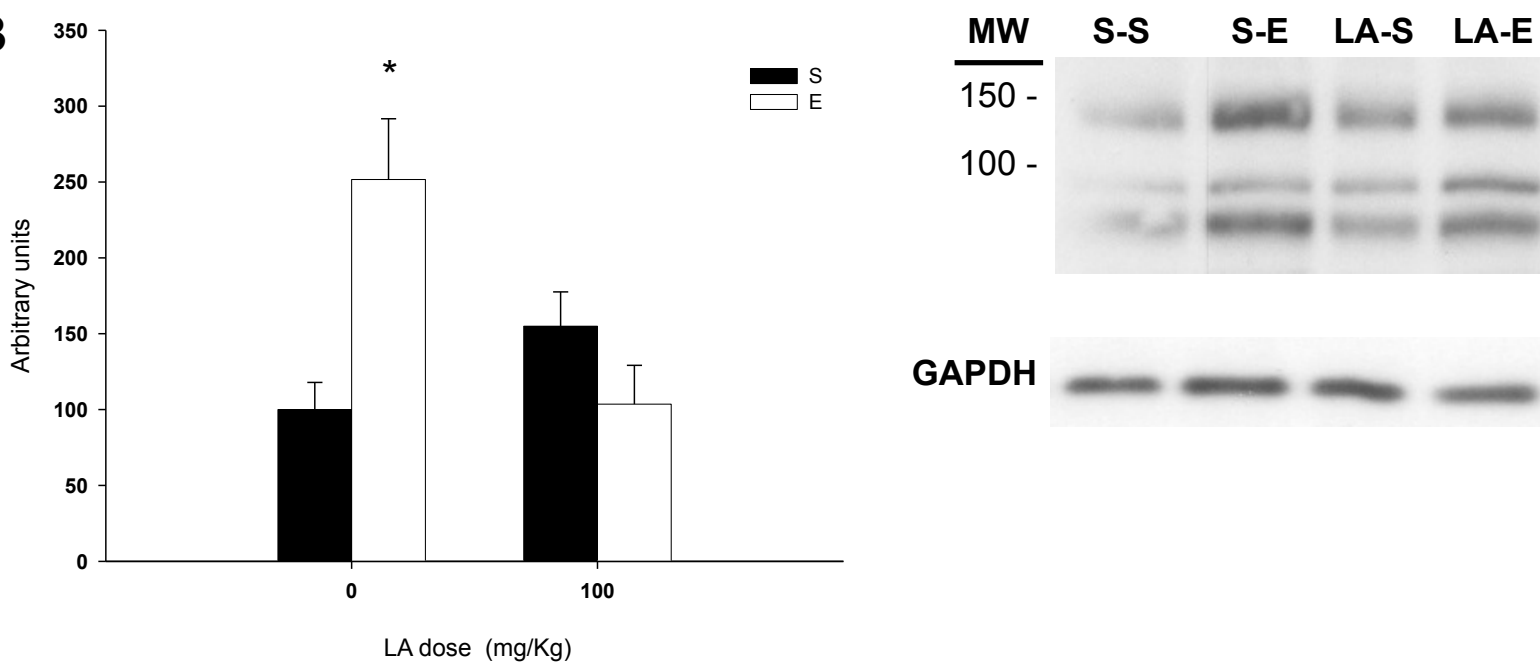

GAPDH
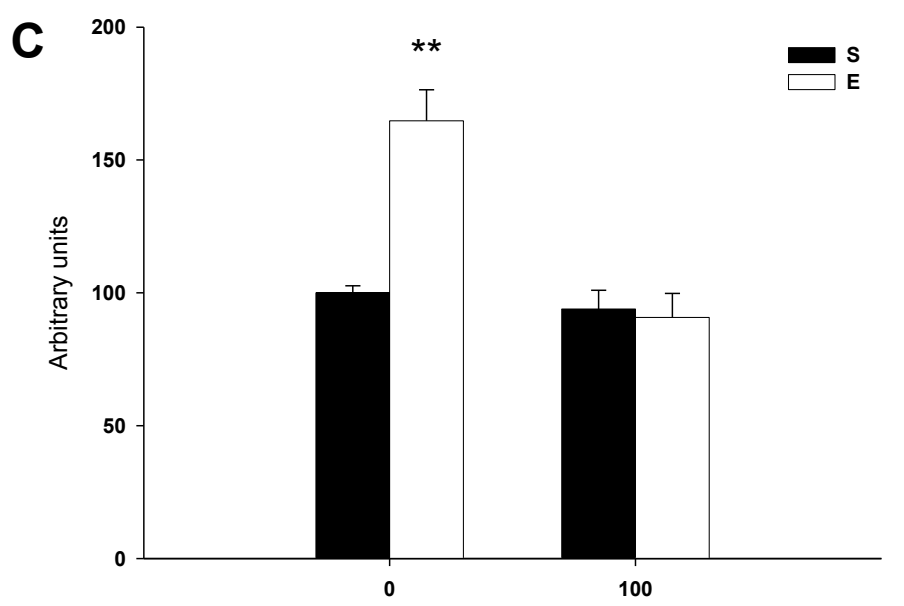

S-S S-E LA-S LA-E

150 -

100 -

GAPDH

LA dose $(\mathrm{mg} / \mathrm{Kg})$ 100 -

GAPDH
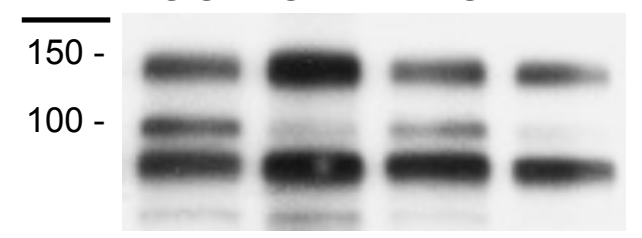

(x) 
Figure 2
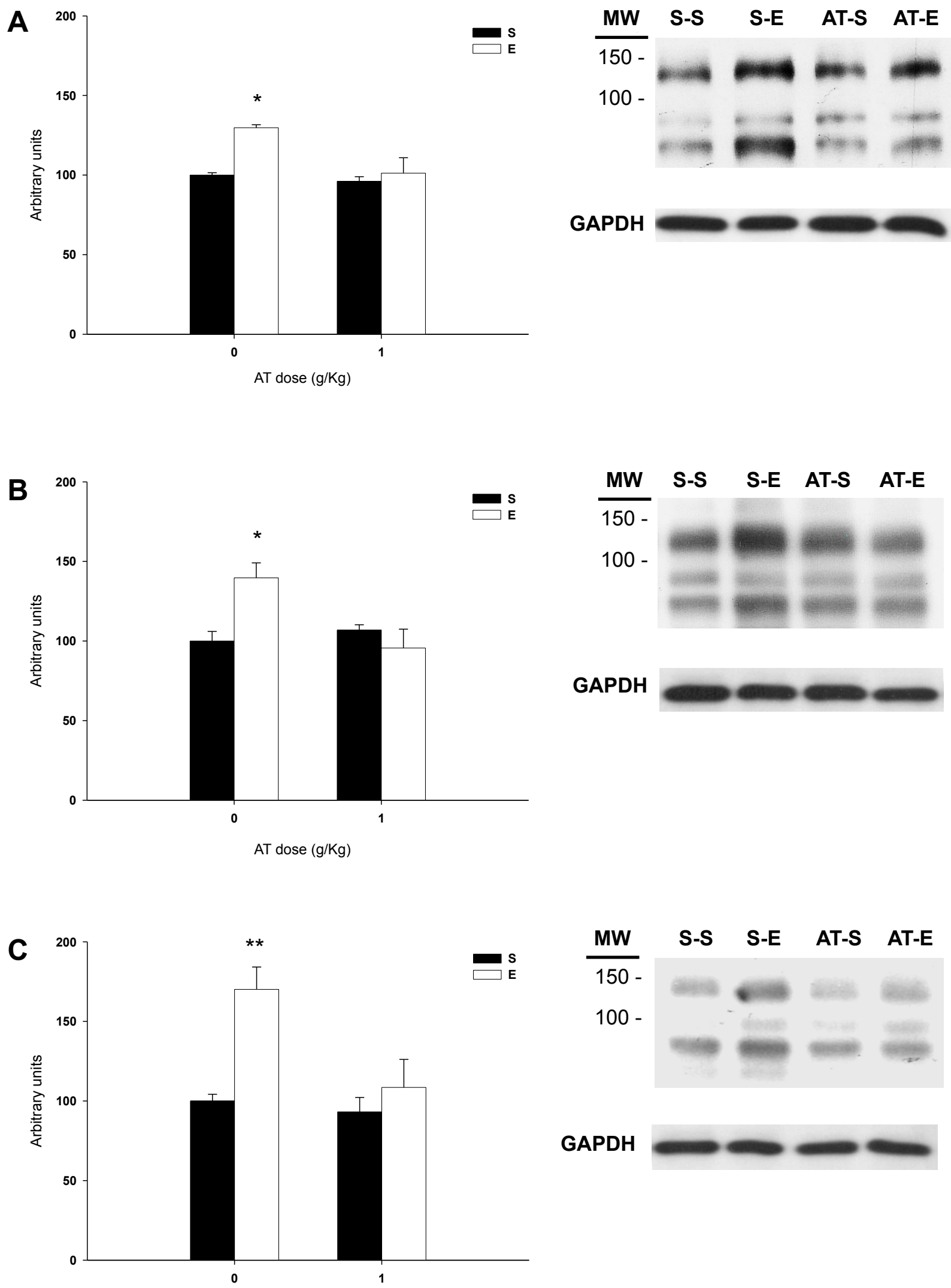

GAPDH 
Figure 3

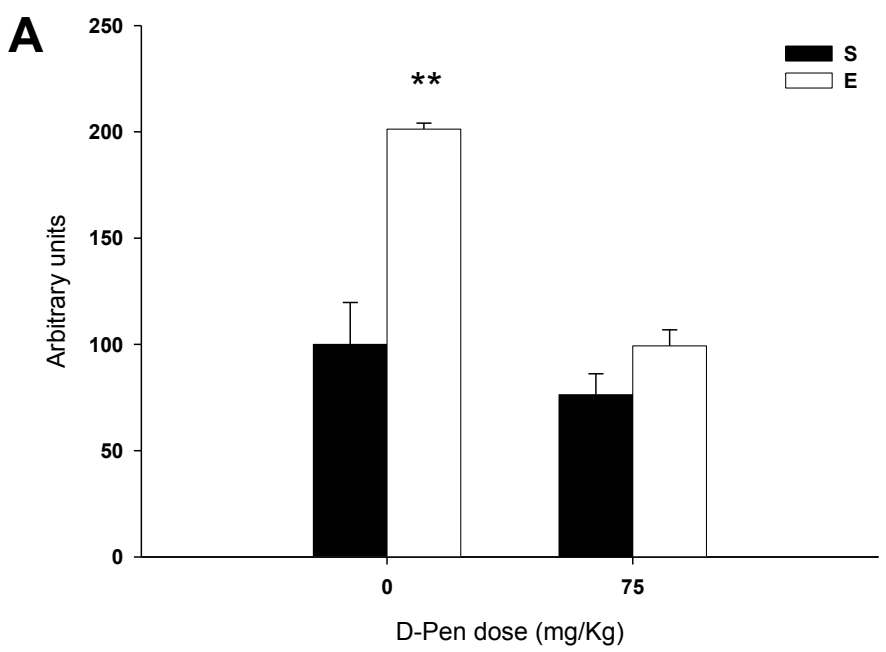

GAPDH

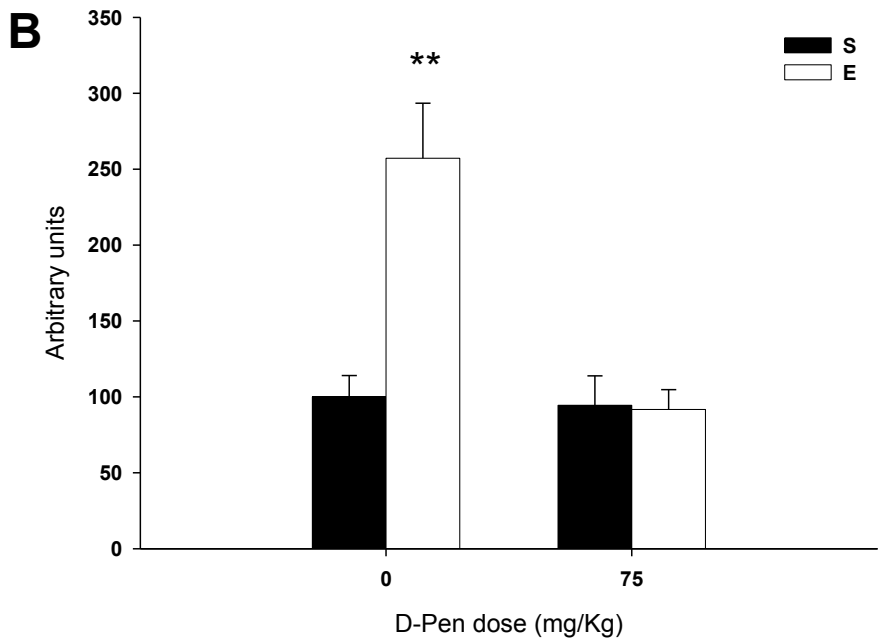

GAPDH

MW S-S S-E S

$\overline{150-}$

100 -
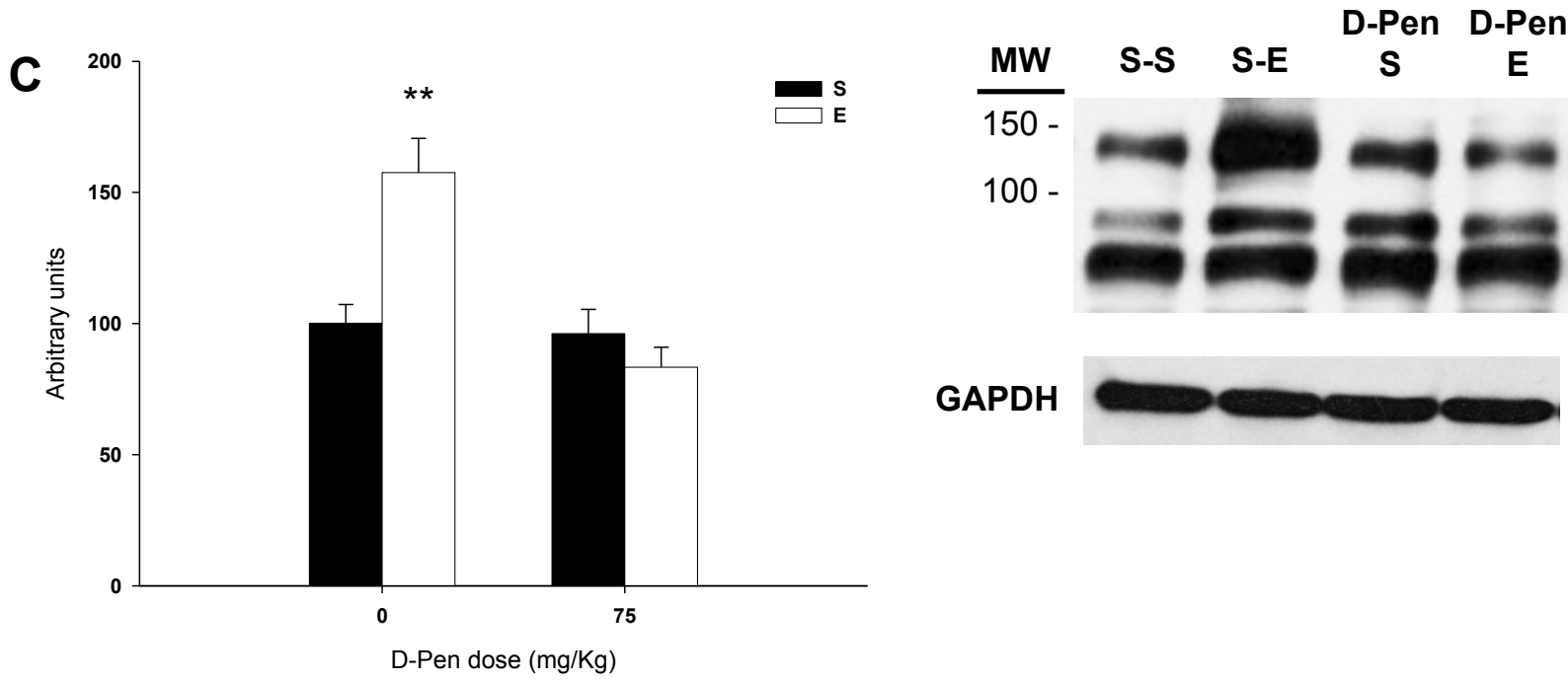

GAPDH 